\title{
Chinese and US Kinetic Energy Space Weapons and Arms Control
}

\author{
Mark A. Gubrud
}

A number of gaps divide reality from perception concerning the kinetic energy ballistic missile defense and antisatellite (ASAT) weapons developed, tested, and possessed by the United States and China. This article explains the equivalence of these supposedly distinct classes of weaponry, and reviews the diplomatic history surrounding recent Chinese and US tests of them, particularly in the light of recent WikiLeaks revelations. The inadequacy of arms-control proposals that would address only the testing or use of these weapons as ASATs is discussed, and a more substantive proposal is offered that emerged in a recent meeting between Chinese and US arms-control analysts. KEYWORDs: antisatellite weapons, arms control, ballistic missile defense, Chinese military, WikiLeaks.

When China caused the intentional Collision of tWo objects in outer space on January 11, 2007, its "experiment"-unambiguously a test of an antisatellite (ASAT) weapon - was widely condemned as provocative and irresponsible. The target, the seven-year-old weather satellite FY-1C, had been stationed in a nearly circular orbit at an altitude of $860 \mathrm{~km}$, and most of the debris from the collision continued along trajectories near that of the satellite. This debris remained in low-Earth orbit (LEO) at altitudes concentrated between 500 and $1,500 \mathrm{~km}$ but ranging as low as 200 and as high as $4,000 \mathrm{~km}$. It spread out to fill, and to pose a threat to satellites orbiting anywhere within the entire LEO sphere. ${ }^{1}$ By 2010 NASA reported that 2,841 pieces of this debris had been cataloged, 97 percent of which remained in orbit. As many as 35,000 more pieces were too small to be observed from Earth. The FY-1C debris accounted for "about $18 \%$ of the entire population of cataloged man-made objects in orbit" and was "the greatest amount of orbital debris" ever produced in a single event, more than twice that left by the accidental Cosmos-Iridium satellite collision two years later (NASA 2010). 
The test was not announced by China, and news of it only surfaced a week later, leaked from US sources (Covault 2007). The information was confirmed by a US spokesman the next day, and the following day "protests and expressions of concern were lodged over the test by the United States, Japan, Canada, South Korea and Australia," later joined by Britain, Taiwan, India, South Korea, and the European Union (Elegant and Thompson 2007; Hitchens 2007). The United States had in fact protested to China in Beijing and Washington on January 15 (WikiLeaks 2011d). However, the Chinese ministry of foreign affairs did not acknowledge that the test had taken place until January 23 (Yu 2007). Earlier, its spokesman had stated that the ministry "had not been informed" (DPA 2007). As Gregory Kulacki and Jeffrey Lewis comment, "China's failure to present a timely, cogent explanation to the world magnified the test's negative consequences by making the Chinese government appear careless, indifferent, and disorganized" (2008, 338).

Exactly three years later, China conducted a second collision test of a similar, identical, or improved version of the same weapon. Much of what we know about this is contained in a January 12, 2010, US State Department cable released by WikiLeaks (WikiLeaks 2011b). ${ }^{2}$ According to that document, the target was a CSS-X-11 ballistic missile (BM) launched from the Shuangchengzi Space and Missile Center. ${ }^{3}$ The interceptor was carried by an SC-19 rocket launched from the Korla Missile Test Complex, two minutes and forty-two seconds later. ${ }^{4}$ The collision took place at an altitude of $250 \mathrm{~km}$, about five minutes after the launch of the interceptor. In the second test, both objects were traveling on BM-like trajectories, and would have fallen to Earth soon in the absence of a collision. After the impact, which also took place at a relatively low altitude, debris pieces followed trajectories close to those of the objects from which they were created, and therefore quickly reentered Earth's atmosphere. As the State Department cable noted (one day later), "No debris from this test remains on-orbit."

This time, China was much better prepared for any foreign reaction, and instead of taking two weeks to acknowledge the test, announced it promptly through the official news agency Xinhua, reporting that "the test has achieved the expected objective" (Xinhua 2010). Given the lack of hazardous debris created by the second collision test, international reaction was comparatively muted. But there 
was good reason to doubt Xinhua's assertion that "the test is defensive in nature and is not targeted at any country." Although the second collision test was called by China "a test on ground-based midcourse missile interception technology," information gained about the performance of the weapon would be completely applicable to its use against a satellite.

As this article shows, ballistic missile defense (BMD) weapons of the type first developed by the United States, and tested by China in January 2010, are so closely related to kinetic energy antisatellite (KE-ASAT) weapons that the two are in many cases indistinguishable. Although tests against satellites and against missile targets are distinguishable by definition, this distinction has little or no technical significance for the weapons involved, and testing against one type of target can fully satisfy requirements for development and validation of weapons for use against either type of target. This is a fact that must be taken into account when considering the implications of any such testing and when proposing any arms control measures intended to prevent a space arms race.

\section{Doublethink, Doubletalk}

One would think the United States could hardly object to China conducting such a test, since the United States itself has carried out many such tests, beginning with the Homing Overlay Experiment in 1984. Moreover, the United States has developed and operationally deployed several weapons systems with similar capabilities, including the Theater High Altitude Air Defense (THAAD), the Ground-Based Midcourse Defense (GMD), and Aegis Ballistic Missile Defense Standard Missile-3 (SM-3) (Samson 2010). These systems have been tested against targets in space at least four dozen times since $1999 .{ }^{5}$

Nonetheless, on January 12, 2010, the US embassy in Beijing was sent an "action request" to demarche the Chinese ministry of foreign affairs on US concerns about the second Chinese test. The cable explained, as background, that

an SC-19 was used previously as the payload booster for the January 11,2007 , direct-ascent anti-satellite (DA-ASAT) intercept of 
the Chinese FY-1C weather satellite. Previous SC-19 DA-ASAT flight-tests were conducted in 2005 and 2006. This test is assessed to have furthered both Chinese ASAT and ballistic missile defense (BMD) technologies. (S//NF) Due to the sensitivity of the intelligence that would have to be disclosed to substantiate the U.S. assessment, the U.S. Government in its demarche to the PRC Government will not associate the January 2010 SC-19 intercept flight-test with past SC-19 ASAT flight-tests. The United States will request assistance from our Asia-Pacific allies Australia, Japan, and the Republic of Korea in demarching China in a fashion similar to the U.S. approach. (WikiLeaks 2011b; emphasis added) ${ }^{6}$

The reader may judge whether the intent was to elide the issue of US testing of equivalent weapons with both BMD and ASAT capabilities, or whether in fact sensitive intelligence is required to discern the applicability of BMD technology to an ASAT program. In either case, the inclusion of the marker "S//NF" (secret, not releasable to foreign nationals) indicates that the Obama administration really did not want this issue discussed publicly, in diplomatic exchanges with China, or even with the "allies" to be enlisted in "demarching China in a fashion similar to the U.S. approach."

As outlined in the cable, the US approach to demarching China consisted of questions about the "direction of China's BMD program." Did China view missile defense as contributing to deterrence and stability? Whose missiles was the program intended to defend against? Since China would obviously not want to give straight answers to these questions, the questions suggest skepticism that the test was in fact part of a BMD program. ${ }^{7}$ The US diplomats were also to ask, "What steps were taken to minimize the creation of orbital debris?" This question is clearly disingenuous, since the obvious answer is that they tested it against a ballistic missile, at low altitude, instead of a satellite. However, if "asked about the Obama Administration's position regarding China's earlier direct-ascent anti-satellite flight-test," US diplomats were to reply that US concerns about the earlier test were still valid, and that "the United States has steadfastly urged China not to conduct further anti-satellite weapons flight-testing in space."

US concerns expressed to China in January 2007 were not limited to debris. They included the objection that the test of an ASAT "did 
not square with China's stated position of not wishing to embark on any kind of arms race in outer space." This is revealed in a cable dated January 6, 2008, in which Washington instructed its diplomats in "Berlin, Canberra, London, Ottawa, Paris, Rome, Seoul, Tel Aviv, and Tokyo" to ask those governments to relay another message to China, complaining again about the debris but going further to emphasize that

- The United States considers space systems to have the rights of unhindered passage through, and operations in, space without interference.

- Any purposeful interference with U.S. space systems will be interpreted by the United States as an infringement of its rights and considered an escalation in a crisis or conflict.

- The United States reserves the right, consistent with the UN Charter and international law, to defend and protect its space systems with a wide range of options, from diplomatic to military (WikiLeaks 2011c).

The overtly threatening tone of this message may have been intended to have an effect both on China and on the allied governments. The United States wanted allies to seek answers to questions about China's ASAT program: Would there be "further tests of a directascent antisatellite weapon or other antisatellite weapons, capabilities, or technologies? Would any of these be operationally deployed? If the US allies asked about US rejection of the Russian-Chinese proposal of a Treaty on Prevention of Placement of Weapons in Outer Space, they were to be urged not to support that initiative. It was to be pointed out to them that "the draft treaty would not prohibit the development and deployment of a ground-based direct-ascent interceptor of the type of ASAT China tested last year." No answer was specified to any questions about why the United States had not responded by proposing a more comprehensive space arms-control agreement. Allies were to be told that "the United States does not have any 'weapons' in space, nor do we have any plans to field such weapons." If allies asked about US missile defense, they were to be told, "The U.S. missile defense system is strictly a defensive system."

The last claim was true, unless, of course, the US missile defense 
system were to be used in an offensive role, such as to destroy a satellite. Perhaps the most hypocritical assertion to be conveyed to allies was that "the United States has not conducted an antisatellite test since 1985." The 1985 test of the F-15-launched Miniature Homing Vehicle was indeed the only time in history that the United States had intentionally destroyed a satellite in orbit. But even as this demarche-through-allies was being launched at China, the United States was already preparing for its second "satellite shootdown."

\section{Proven but Denied: BMD and ASAT Weapons}

\section{The US Satellite Intercept of 2008 and China's Reaction}

On February 21, 2008, the United States used a ship-launched SM-3 missile to intercept an intelligence satellite known as NROL-21, or USA-193, which had suffered an apparent failure of all systems after launch. The plan to intercept the satellite was not announced publicly until just six days before the shot, although news had been leaked a few days earlier (Fulghum 2008). This gave foreign and domestic opponents little time to voice any objections. The target was in a decaying orbit, nearing reentry, and the collision took place at an altitude of $247 \mathrm{~km}$ (close to that chosen by the Chinese, perhaps not coincidentally, for their second intercept test two years later) (US Department of Defense 2008). At such low altitude, even if the target is on an orbital trajectory, the debris particles, with much lower ballistic coefficients (ratio of mass to aerodynamic drag) than an intact satellite, almost immediately reenter the atmosphere.

Although the stated justification for the intercept was to destroy the satellite's fuel tank, filled with half a ton of frozen hydrazine, there were many reasons to doubt this rationale. The tank would undoubtedly have ruptured and the hydrazine burned on reentry. ${ }^{8}$ Even if some of the hydrazine had made it to the ground, its toxicity is similar to that of ammonia, and the acrid smell, on top of the crash and likely fire, would probably have sent survivors fleeing. If one makes a cautious estimate that whatever was left of the tank and hydrazine ice ball would kill anyone found within a seven-meter radius of its impact point, its chance of killing at least one person was 
about one in a thousand. ${ }^{9}$ The intercept operation was publicly projected to cost the US government $\$ 40-\$ 60$ million, but final costs were reported at $\$ 112$ million (McIntyre 2008; InsideDefense.com 2008). Thus, although US officials insisted the purpose of the shot was to save human life, the cost per life saved was extraordinarily high, and the overwhelming probability is that no life would have been lost if the satellite had been allowed to make an uncontrolled reentry.

If the USA-193 antisatellite operation is inadequately explained by a concern for human safety, what it certainly did accomplish was to underscore US threats to "defend and protect its space systems with a wide range of options" by demonstrating that the United States could still do what it had done in 1985 - and what China had only done in 2007. ${ }^{10}$ Moreover, it showed that the United States possessed that capability in the form of highly developed, tested, and operationally deployed weapons systems.

Chinese reactions to the intercept showed a keen understanding of its implications. China was only informed of US intentions on February 15 in a demarche which, incredibly, warned "that China should not use the U.S. satellite-interception event as an excuse to conduct further anti-satellite tests" (WikiLeaks 2011a). In a February 21 press briefing, Ministry of Foreign Affairs spokesman Liu Jianchao said that "China is continuing to closely follow the possible harm caused by the U.S. action to outer space security and relevant countries" (Xinhua 2008; emphasis added). According to another leaked US cable,

several academics say that much of the PRC public and official response to the event is driven by their anger over the berating the PRC received after their January 2007 ASAT test. . . [ [However,] Dr. Teng Jianqun, Deputy Secretary General of the China Arms Control and Disarmament Department, took a different point of view, instead citing the U.S. "rejection" of the 12 February joint PRC-Russian proposal for a treaty banning weapons in space as the incendiary driving PRC anger. "This shoot-down proves the U.S. missile defense system is also an offensive system," he said. . . . Dr. Teng described the shoot-down as unnecessary and simply an opportunity to test the U.S. missile defense system. (WikiLeaks 2011c) 


\section{Questionable US Explanations}

Despite numerous reports that the SM-3 missile was "modified" and would not normally have been able to engage a satellite, General James Cartwright, vice chairman of the Joint Chiefs of Staff, stated after the shot that the only physical modification to the missile had been for purposes of telemetry - that is, not to enable the intercept but only to collect data about it (Cartwright 2008). The mission was modeled and gamed to ensure the highest likelihood of success, and "software" was reportedly changed, but it is very unlikely that this refers to anything but data tables for optimized target recognition, aim point, and intercept geometry selection. Changes to the real-time software that controls the missile's various systems would be risky, and there is no reason to think that any such changes would be necessary. The fire control system was also networked to remote sensors that provided cuing and target tracking data, so that launch of the missile did not need to depend solely on the ship's onboard radar. This capability was not previously a feature of the Aegis Ballistic Missile Defense System, but as of 2011 it is being permanently incorporated as "launch on remote" (Brinton 2011; O'Reilly 2011; "Sea-based Missile Defense Flight Test" 2011).

US denials that the SM-3 represents an operational ASAT weapon are not entirely unfounded. The missile in its Block IA and more recent IB versions is believed to have a fairly low burnout speed, about $3 \mathrm{~km} / \mathrm{s}$, and is therefore unable to engage satellites at altitudes higher than about $400 \mathrm{~km}$. Although a few militarily significant satellites may be within its range, the bulk of important targets are found at higher altitudes. However, the follow-on SM-3 Block IIA and IIB versions, slated to be introduced in 2015-2020, would have a larger booster and higher burnout speed, ostensibly to enable them to engage longer-range BMs but also giving them the ability to intercept a large majority of satellites in low-Earth orbit (Grego and Wright 2010, 22). As a sea-based system, the SM-3s could potentially be dispersed around the globe to enable a prompt sky-sweeping strike.

Meanwhile, the several dozen interceptors (thirty as of 2011) of the GMD system have burnout speed reported in the range of 5.5-6 $\mathrm{km} / \mathrm{s}$, and hence pose a threat to essentially all LEO satellites (up to altitudes of 1,500-2,000 km) (Missile Defense Agency 2011; Clare- 
mont Institutes undated). The Lightweight Exoatmospheric Projectile (LEAP) warhead used in the SM-3 and the somewhat larger Exoatmospheric Kill Vehicle (EKV) used in the Ground-Based Interceptor (GBI) are essentially the same technology, and both are made by Raytheon Corporation. There is no reason to doubt that the GMD/GBI can intercept satellites within its range if it can intercept missiles.

In fact, BMD is usually considered the harder mission. One retired Chinese general commented that "satellite interception is like shooting a beer bottle. Missile interception is like shooting ducks" (Chen 2010). According to the report in which he was quoted, this is because "the defence system had to identify the location and trajectory of the missile. Because of the speed of the warhead, the time for response including detection, aim and launch was a matter of minutes." That is a fair statement of some of the problems an operational BMD system faces, as compared with an ASAT weapon, which might be pretargeted on a satellite known to follow a predictable trajectory. But of course, China's 2010 test may not have been operationally realistic; US BMD tests usually are not.

More significant is the fact that BMs, and especially their separated warheads, present smaller and less observable targets than most satellites of interest. Hitting them therefore imposes greater demands on the sensitivity and resolution of homing sensors and the precision and speed of terminal guidance and divert thrusters. Consider that a closing speed of $10 \mathrm{~km} / \mathrm{s}$ implies that 1 second prior to impact, the target is still $10 \mathrm{~km}$ away. If the aim of the interceptor is off by $30 \mathrm{~cm}$, it may completely miss a BM or warhead, whereas the larger crosssection of a satellite presents a more forgiving target. In addition, given constraints on interceptor basing and the narrow window for destruction of a ballistic missile before it reaches its target, the BMD mission may require a high closing speed, whereas ASAT strike planning may provide more opportunities for choosing intercept geometries that moderate closing speeds. ${ }^{11}$

It may be unlikely that the United States would ever use its hitto-kill kinetic energy BMD (KE-BMD) systems as debris-creating kinetic energy ASAT (KE-ASAT) weapons. But the capability is there, and it is difficult to be sure what the United States would consider doing when facing the prospect of a hot war with a nuclear-armed na- 
tion. In particular, Chinese photoreconnaissance, radar, and signals intelligence satellites might enable the targeting of anti-ship ballistic missiles (ASBM) or other weapons on the US fleet in the event of a crisis in the Western Pacific. Although the United States may have other means of addressing this threat, one of the fastest and surest ways to disable a LEO satellite is with a KE ASAT. It is also fair to ask how US military analysts would view Chinese possession of an ASAT-capable arsenal comparable to the existing GMDs plus planned Block II SM-3s.

\section{BMD Testing and ASAT Testing}

Not only can BMD weapons be used to destroy satellites, but testing against targets in ballistic missile-like trajectories can fully support the needs of a program intended to develop and perfect these weapons for use in ASAT missions.

A number of misconceptions lead to confusion about this point. For example, it is sometimes said that ballistic missiles fly on parabolic trajectories, but in fact both BMs and satellites travel on elliptical trajectories after booster burnout. Therefore, the implication that different algorithms would be needed to predict the motion of each class of target is false. In fact, in the endgame just before the intercept, both the interceptor and the missile or satellite will be in freefall, apart from the interceptor's small corrections to its course. This means that the interceptor can almost completely ignore gravity in the crucial final seconds since it affects target and interceptor equally.

Satellites may travel faster than ballistic missiles, which would seem to make them harder targets. The horizontal velocity of a satellite in circular orbit at $500 \mathrm{~km}$ altitude is $7.6 \mathrm{~km} / \mathrm{s}$ in the Earth frame of reference - that is, relative to the Earth's center-whereas for longrange ballistic missiles it will be in the range of 3-7 km/s. However, KE-BMD/ASAT interceptors may close on their targets in a wide range of geometries, as viewed in the Earth frame. They may appear, in the Earth frame, to make a head-on collision, in which case the closing speed is the sum of interceptor and target Earth-frame speeds. Alternatively, one object (possibly the target) may appear to overtake the other, as both travel in the same horizontal direction. In this case, 
the closing speed is the difference of the two Earth-frame speeds. Between these two limiting cases, the objects may appear to collide at any angle.

I use the word "appear" here because this is just how the geometry of the intercept appears in some frame of reference, such as that of the Earth's center, or that of some point on the Earth's surface. From the point of view of each object, the other object comes straight at it, at some closing speed that is the (magnitude of the) difference of the two objects' vector velocities. In this sense, all collisions in space are always head-on. The interceptor orients itself so that its axial homing sensor (telescope) is pointed directly at its target. Which aspect of the target is impacted depends on the target's orientation, which may affect the interceptor's chance of success, since the shape, cross-sectional area, shading, and reflectivity of the target may vary with its orientation.

Thus, by choice of the intercept geometry, the closing speed can often be reduced, or alternatively the aspect of the target to be impacted can be chosen in order to increase the chance of a successful intercept. The ASAT mission will generally allow more flexibility to choose a favorable geometry than is the case for BMD, where for given missile and interceptor launch points the missile must be intercepted before reaching its target.

The ASAT mission can be formally distinguished from BMD by definition: A satellite is an object in an orbital trajectory, that is, a state of inertial motion such that, with gravity the only significant external force acting upon it, the object will complete at least one revolution around the Earth. However, for LEO — that is, altitudes below about 2,000 km - this state of motion constitutes a narrow band of the parameter space consisting of altitude and horizontal and vertical components of Earth-frame velocity. From the point of view of hitting the object with a homing interceptor at some high closing speed, it matters little whether the object resides inside or outside that narrow orbital band. Rather, a large number of factors affect the likelihood of success. These include:

- Launch point, launch timing, acceleration, and burnout speed of the interceptor's booster.

- Trajectory and altitude of the target. 
- Capabilities of the interceptor's homing sensor(s).

- Whether the target is illuminated by the Sun and from what direction.

- Whether the interceptor approaches the target from above and views it against Earth, and whether the Earth is sunlit or not, or whether the interceptor can approach from below, or horizontally, and view the target against the blackness of space.

- The shape, temperature, emissivity, and reflectivity spectrum of the target.

- Closing speed of the intercept, relative to the overall speed and accuracy of the interceptor's homing system.

Realistically, any operational ASAT weapon or BMD needs to be capable in as wide a range of circumstances as possible. For the variables that most strongly affect performance, the ranges within which the system must perform well overlap broadly for ASAT and BMD missions. The most stressing circumstances occur more often for the BMD mission, so a thorough KE-BMD testing program will effectively cover all testing requirements for KE-ASAT development and perfection. Without ever testing against an actual orbital target, engineers will be able to assure military and national leaders that a given weapon system can be used against satellites with an effectiveness determined by overall system reliability and not reduced by any unknowns due to the lack of testing against specifically orbital targets. This is no more uncertain than whether US ballistic missiles can reach targets in China on the basis of tests targeted at Kwajalein atoll.

\section{ASAT-Only Test Bans}

\section{A Critique of Recent Proposals}

In light of the equivalence of ASAT and BMD weapons and testing, proposals to control one but not the other will not achieve effective control of either. Nonetheless, US analysts often take it as given that BMD testing cannot be restricted, and some argue that a narrow KE-ASAT "test ban" would still be an effective and highly verifiable arms-control measure. For example, Bruce W. MacDonald has 
advocated "a ban on any space testing that creates significant debris. ... This option would seek to discourage the development of KEASAT weapons by banning testing against orbiting objects. Carefully crafted language need not constrain missile defense testing" (MacDonald 2009b, 7). Without addressing the arguments raised here, MacDonald claims, "By banning such ASAT tests, states could never have the level of confidence in such weapons that they would probably need in order to rely upon them in a major conflict" (MacDonald 2009a, 21).

From a technical perspective, this is almost certainly not true. Testing against BM targets can provide enough information about the performance and reliability of an interceptor under a wide range of conditions that essentially no further information would be gained by testing against an orbital object. At best, one may hope that political decisionmakers would remain doubtful and therefore reluctant to launch an escalating, preemptive, or surprise attack. But scientists would be able to tell them that a thoroughly tested BMD system can engage satellites within its reach, and for a mature system, they would be able to confidently predict a high success rate.

Furthermore, Geoffrey Forden points out that a ban on impacts only would allow ASAT weapon development to proceed on the basis of "flyby" tests in which the interceptor is programmed to miss the target by some distance vector that is small enough to be accurately measured by telemetry from the interceptor's own sensors (Forden 2007). Essentially, if the interceptor is able to pass through a designated point in relation to and close by the target, it could as well have hit the target had it been instructed to do so. In order to frustrate this testing mode, Forden proposes "to ban one spacecraft from approaching another orbiting spacecraft at excessive speeds," suggesting that "excessive speed" be defined as greater than $100 \mathrm{~m} / \mathrm{s}$ closing speed, and that the ban would apply when the "approaching" spacecraft was within $100 \mathrm{~km}$ of the orbiting spacecraft and using its thrusters to guide the "approach." One problem with this idea is that it would appear to forbid spacecraft from using their thrusters at the last moment to avoid a collision. Another is that it is not uncommon for active satellites (and debris) in LEO to pass at less than a 100-km distance, so the meaning of the term "approach" remains ambiguous. But these issues could be resolved by further construction of the pro- 
posal. The deeper problem is that Forden's proposal is intended to permit continued BMD testing, since it only applies when at least one of the objects is orbital, which, as we have seen, would render it technically ineffective.

A more sophisticated proposal from Ross Liemer and Christopher Chyba points out that the US Missile Defense Agency (MDA) has apparently already imposed upon itself an altitude ceiling as low as $230 \mathrm{~km}$ for BMD intercept tests (Liemer and Chyba 2010, 156). As seen in the USA-193 intercept, collisions at such low altitude do not create long-lived debris even when one of the objects is actually orbital. For ICBM intercepts at higher altitudes, where the trajectory of the ICBM is very close to orbital, nearly all of the debris will be nonorbital and will quickly reenter, but some small amount of debris may be boosted into orbital trajectories by the energy of the collision. Therefore, to avoid any production of long-lived orbital debris, or criticism for risking its production, MDA prefers to conduct intercepts at low altitude.

Nothing is lost by adherence to this restriction. The GMD interceptors have burnout speed comparable to that of an ICBM. While a typical combat engagement might take place at $700 \mathrm{~km}$ or greater altitude, faithful simulation of the conditions of such an intercept can be achieved, if desired, by using energy management maneuvers such as flying the rocket in a zigzag or spiral motion in order to waste some of the booster's speed (which would have otherwise gone into reaching higher altitude). ${ }^{12}$ Similarly, tests at this low altitude also verify the capability of the interceptors against satellites at the higher altitudes that they are capable of reaching. In fact, an ASAT weapon with an upper stage capable of reaching geosynchronous orbit (GEO) could be fully tested with collisions only below $250 \mathrm{~km}$ and perhaps a few nonintercept flights to GEO.

Liemer and Chyba suggest that an altitude limit of 250-300 km for all collision tests, regardless of whether any orbital objects were involved, would constitute a verifiable "limited test ban" comparable in spirit to the 1963 Treaty Banning Nuclear Weapon Tests in the Atmosphere, in Outer Space and Under Water (known as the Limited Test Ban Treaty). The primary impetus to that treaty was the worldwide demand for an end to above-ground nuclear weapons tests, which were adding significantly to the burden of radioactivity in the 
human environment. Similarly, Liemer and Chyba argue that their "limited ban ... would be both an arms control measure and an environmental measure to decrease debris collision risk for astronauts and space systems" (Liemer and Chyba 2010, 154-155).

However, it is difficult to see the effectiveness of the "limited test ban" as an arms-control measure since, as Liemer and Chyba admit, it "would permit all countries to test debris-producing ASAT systems below the agreed altitude" $(2010,156)$. Moreover, as evidenced by the 2010 Chinese intercept test, following the storm of criticism China endured in 2007, it seems unlikely that China, India, Russia, France, or any other nation that wished to test a KE-ASAT in the near future would choose to do so against an orbital object at high altitude. ${ }^{13} \mathrm{Un}$ less it deliberately wished to demonstrate its readiness to use such a weapon in spite of international opprobrium, it would more likely test at low altitude either against a target on a BM-like trajectory or against a target launched into a very low orbit just for the occasion. Therefore it is not clear what would be achieved by formalizing the present de facto moratorium as a treaty; ironically, doing so might legitimize testing below the altitude limit, and thereby encourage the development of KE-ASAT/BMD weapons by more and more states. We might recall that the 1963 "test ban" did not slow nuclear weapons testing and proliferation, but only moved it underground. ${ }^{14}$

\section{Confidence Building and a Code of Conduct}

While a low-altitude test limit for ASAT weapons and BMD might be described as a confidence-building measure, a reasonable question to ask is: confidence in what? Not that states do not possess ASAT-capable weapons. Not that they are not testing and perfecting them. Not that they would not consider their use under some circumstances. At best, one can say that adherence to a low-altitude test limit would avoid both the production of persistent space debris and the political fallout of tests that produce it. But nations will likely adhere to such a limit even without any treaty, while tests that demonstrate the development, perfection, and possession of ASAT-capable weapons would likely provoke reciprocal military responses whether they were sanctioned by a treaty or not.

Another version of an ASAT test ban is incorporated into the 
Code of Conduct for Outer Space Activities, which has been proposed by the Council of the European Union (EU). Conceived as "a set of best practices aimed at ensuring security in outer space," adherence to the code is to be voluntary and undertaken by the subscribing states without obligation or prescribed penalties for noncompliance. Accordingly, the council-approved draft of the code from December 2008 calls on subscribing states to "refrain from any intentional action which will or might bring about, directly or indirectly, the damage or destruction of outer-space objects unless such action is conducted to reduce the creation of outer-space debris and/or justified by imperative safety considerations" (Council of the European Union 2008). With the understanding, rooted in existing space law, ${ }^{15}$ that "outer space objects" include satellites (on orbital trajectories) but not ballistic missiles (on nonorbital trajectories), this language may be taken to proscribe the use of any weapon as a KE-ASAT, unless such an action is "justified by imperative safety considerations."16 The 2008 draft, adopted following the USA-193 shot, seems to acknowledge and approve of the given justification for that action. However, in order to be able to damage or destroy an outer-space object when justified by imperative safety considerations, a Subscribing State would need to possess the appropriate means of doing so. Thus, even if the code can be read as restricting the testing and use of ASATcapable weapons, it clearly does not ban their development or possession, or their testing against non-outer space objects, which as we have seen is sufficient for their perfection as weapons against outerspace objects.

The October 2010 revision of the EU draft Code of Conduct goes further, revising the paragraph quoted above to read

refrain from any action which intends to bring about, directly or indirectly, damage, or destruction, of outer space objects unless such action is conducted to reduce the creation of outer space debris and/or is justified by the inherent right of individual or collective self-defence in accordance with the United Nations Charter or imperative safety considerations. (Council of the European Union 2010; emphasis added)

This language would appear to legitimize not only the development and possession even of destructive ASAT weapons, but also their 
use, not only when justified by "imperative safety considerations" but also when "justified by the inherent right of individual or collective self-defence" - that is, in warfare. ${ }^{17}$ Thus, the code can no longer be seen as even an ineffective arms control measure; its only function is to ask that subscribing states test their ASAT weapons in a non-debris creating way, while their use in "individual or collective self-defence" is explicitly allowed, overriding even concerns about debris creation.

While the Obama administration has indicated it is considering adoption of the code or a similar measure, there appears to be no prospect that the administration will do so prior to the presidential election in November 2012. ${ }^{18}$ Meanwhile, China has expressed no great enthusiasm for the code. ${ }^{19}$ As we have seen, the code would do little or nothing to slow or stop the development and acquisition of ASAT weapons and other space weapons; it would at best dampen perceptions of an arms race, and hopefully encourage further cooperative measures.

\section{What Can Be Done?}

A more substantive measure, which could be taken bilaterally by the United States and China, would be a voluntary moratorium by both nations on all intentional collisions of objects above the atmosphere. ${ }^{20}$ This would be in effect a moratorium on both BMD and ASAT-mode tests. Like proposed ASAT-only test bans, it would be highly verifiable by national technical means. Unlike an ASAT-only moratorium, it would have real meaning in terms of arms control, because it would prevent the full validation of any completely new KE-BMD/ASAT weapons while permitting the continued development, reliability, and performance enhancement of existing systems possessed by both sides. It would thus disproportionately impact calculations about potential offensive uses of such weapons both as ASAT weapons and as a BMD "shield" behind which to hide when executing an offensive first strike, while having less impact on the ability of BMD to complicate the calculations of potential aggressors contemplating the offensive use of ballistic missiles.

The suggestion of an exoatmospheric collision test ban emerged in discussions between US and Chinese participants in the Honolulu 
workshop in April 2011. Either side could propose the initiative, and the other side could embrace it without formal commitment. It would serve as a clear pause in the nascent US-China space arms race, and assuming it were sustained, it could later be formalized and globalized either as a stand-alone arms-control agreement or as part of a comprehensive space security convention.

At first glance, the idea of stopping all collision tests of BMD interceptors is likely to be seen by US analysts as a nonstarter. But ironically, critics of BMD have traditionally demanded more and more rigorous testing, while MDA and its predecessor, the Strategic Defense Initiative Organization (SDIO), have been loath to comply. This may, in fact, reflect the priorities of a rational development program. BMD tests are expensive, costing in the range of $\$ 100-\$ 200$ million each. It is not clear that technical progress is strongly tied to a heavy schedule of intercept tests involving actual collisions. Critics have asked why tests have not been operationally realistic or involved simple, known countermeasures that adversaries could easily use to defeat BMD. For example, the attacking missile may dispense a large number of aluminized mylar balloons, all slightly different, one of which contains the warhead. This simple shell game is likely to defeat the radar, infrared, and optical sensors used by US BMD systems, because the balloons would be opaque to these forms of radiation.

Supporters have maintained that basic capabilities, such as "hitting a bullet with a bullet," must be developed and perfected first, and that the capability to discriminate warheads from decoys, and to defeat other CMs, can be added later. However, the capability of US BMD systems, such as the GMD and SM-3, to hit target missiles that are not protected by CMs has already been demonstrated in dozens of tests. The more difficult problems of decoy discrimination and the defeat of other CMs can be fully addressed, if at all, without collision testing, since here the task is simply to identify the correct target, and test analysts will have the benefit of knowing the answer. Between tests, a lot of work is done to analyze results, remove bugs, and try to ensure that the same failure is not repeated. Failures due to malfunction of components rather than overall poor system performance are common. Such failures are embarrassing and undermine whatever deterrent value the BMD systems may 
have, while the problems that cause them could often be detected just as well in noncollision tests.

In fact, many tests are conducted without the intent to complete an intercept. Thrusters and kill-vehicle systems are often assessed in terrestrial "hover tests" and in flight tests without actual targets. As noted previously, BMD/ASAT systems can also be tested in "close flyby" mode, and such tests can not only be fully effective in revealing the hidden design flaws, software bugs, and component manufacturing defects that are the most common causes of failure, but can also provide, to essentially the same level of precision as tests ending in collisions, the sensor and guidance accuracy and overall system performance data needed to enable progressive improvement. Given that the United States has several fairly mature KE-BMD systems that have been tested in dozens of intercepts, a moratorium on collisions would freeze a US advantage, while allowing both nations to continue refinement of their existing designs.

Even with completely unrestricted testing, BMD cannot be relied on to be highly effective, due to uncertainties in how the threat missiles will be used; whether unknown, or known but effective CMs will be employed; and whether all essential components of the BMD system will be operational when needed, or whether some will be undergoing maintenance or will have been degraded by hostile action. The history of rocketry and complex weapons in general suggests that for a mature system, with good quality control, perhaps as much as 90 percent effectiveness would be possible against plain targets in ideal conditions. However, performance will likely degrade in combat. Against realistic threats employing even simple, known CMs, the BMD is likely to prove completely ineffective.

Therefore, there are two realistic objectives for BMD. The first is to provide some level of attrition against cheap conventional missiles without countermeasures. Weapons for this purpose already exist, and, as we have seen, they can continue to be improved without collision testing. The second objective is to strengthen deterrence of any attempt to use a small number of rudimentary missiles, perhaps with nuclear, biological, or chemical warheads, as weapons of terror and blackmail. Here the thinking is that adversaries may view the possession of such missiles as a trump card, enabling them to engage in regional aggression while deterring intervention by a major power. 
They are less likely to do so if the major power acts as if it will not be deterred, and particularly if it creates the impression that there is a significant chance that the missiles would be intercepted or that it believes the missiles would be intercepted. Continual testing of already-proven hit-to-kill capabilities is not needed in order to have this effect, nor is a high certainty of BMD effectiveness-which is not achievable in any case. Rather, testing that openly displays the unreliability of $\mathrm{BMD}$, or which advertises the fact that successful discrimination of warheads from simple decoys has not been demonstrated, undermines the value of BMD to discourage adversary strategies that rely on BMs as deterrents. BMD supporters might therefore be willing to accept a moratorium on collision tests, particularly in light of the fact that failure of such tests is hard to conceal.

\section{Conclusion}

Different levels of confidence in weapons performance are needed for aggressive and nonaggressive purposes. Aggressive use of KEASATs, or weapons developed as BMD but having ASAT capability, requires high confidence in their ability to achieve a prompt knockout; otherwise a preemptive or surprise attack plan may go awry, with potentially disastrous consequences for the attacker. While collision testing against BM targets can provide high confidence in a weapon's effectiveness as an ASAT weapon, tests that do not involve actual collisions will leave greater room for doubt.

Similarly, aggressive plans that involve launching a preemptive strike while relying on BMD to stop any retaliation demand high confidence in the effectiveness of the BMD. However, particularly if its capabilities are unknown, BMD may complicate the calculations of an attacker without the defender needing to have high confidence that the system will function well, as long as the attacker must consider that it might work to some degree. In fact, if testing is confined to flybys and other noncollision forms of testing, the defense can better conceal system performance and any progress that has been made in the defeat of countermeasures. From this perspective, BMD may be expected to "work better" under a total ban on exoatmospheric collision tests. 
A reciprocal moratorium by the United States and China, and to be joined by other nations, on all collision tests above the atmosphere would thus offer real stability. It would pose an obstacle to the development by either nation of completely new KE-BMD/ASAT systems or the proliferation of such weapons to other nations. And it would erode the confidence required to plan aggressive uses of such weapons. Such a moratorium would at the same time avoid undermining the limited deterrent value of BMD, and would not prevent the further refinement of existing BMD systems by means of noncollision testing.

\section{Notes}

Mark Gubrud is adjunct assistant professor in the Department of Physics and Astronomy at the University of North Carolina, Chapel Hill. He has written on emerging technologies and human-security issues, including arms control in space, robotic and nanotechnology weapons, and the popular cult of technology. He can be reached at gubrud@umd.edu.

1. FY-1C was near-polar in inclination, so that the debris fills the entire sphere. However, the threat to other satellites in LEO would be just as great from the destruction of a low-inclination satellite, for which the debris would remain concentrated within a low-latitude band through which all satellites must pass twice per orbit.

2. Various sources report, and the leaked US cable of January 12, 2010, confirms, that the 2007 test may have been preceded by two or three flight tests that were either unsuccessful or had been planned as "fly-bys" to assess system performance.

3. The target missile is described in the cable as a "medium range ballistic missile," that is, a missile with a maximum range between 1,000 and 3,000 km. However, other sources report that CSS-X-11 is a North Atlantic Treaty Organization designator for a missile with a maximum range of about $250-300 \mathrm{~km}$ with a $500 \mathrm{~kg}$ warhead. See, for example, Jane's Information Group 2011 and Globalsecurity.org (undated).

4. Public sources locate Shuangchengzi in north central China, and Korla about $1,200 \mathrm{~km}$ to the west-northwest. A US official had identified the 2007 ASAT interceptor as an SC-19 shortly after that test; see Clinton 2007.

5. Including five since the second Chinese test; see Missile Defense Advocacy Alliance 2011.

6. The term "direct ascent" refers to the fact that a KE-ASAT need not be inserted into orbit but may simply ascend to a point in space (and time) where the target will collide with it.

7. Indeed, US officials publicly voiced doubts that the test was intended for BMD purposes. According to one report, "Under Secretary of State for Arms 
Control and International Security Ellen Tauscher was careful to note the Jan. 11 test was a ballistic missile defense test only in Beijing's portrayal of the event. 'They have asserted that this was a ballistic missile defense test,' Tauscher said. When asked by a reporter whether U.S. officials have doubts about the assertion, she replied, 'We're still looking at that'" (Inside Defense 2010).

8. Reentry would have torn loose the plumbing connections to the tank, and hydrazine, which undergoes exothermic decomposition at moderate temperatures, would have melted and burned where it exited the plumbing and any other ruptures. However, a crude modeling study commissioned by NASA found that reentry heating alone would not have completely ablated the titanium tank. Independent analysts, who obtained the NASA study through a Freedom of Information Act request, unfortunately misread the paper and concluded that its results actually indicated that complete ablation was likely. Much of the ensuing controversy missed the point that even if the tank might have landed fully intact, it posed little risk to human life (Butt 2008; Oberg 2009).

9. The satellite orbit covered a band between $58.5^{\circ}$ North and South latitude, totaling 435 million $\mathrm{km}^{2}$, within which nearly all the world's population of 6.7 billion lived, so that the average population density below the satellite's orbit was about $15 / \mathrm{km}^{2}$. The area of a seven-meter radius circle is $0.00015 \mathrm{~km}^{2}$. The product of these numbers yields an expectation of roughly 0.002 persons killed. However, people do not distribute randomly, but are usually clustered together, and it is not unlikely that on average two or more persons are found within any seven-meter radius circle that contains at least one person. Furthermore, seven meters is likely an overestimate of the lethal radius. Therefore the chance of any fatality, assuming the tank landed intact and loaded with hydrazine, was no more than about 1 in 1,000 .

10. Many commentators speculated that another possible motive for the operation was to prevent classified technology from falling into foreign hands, but it is doubtful that very much of strategic importance could have been learned from the scattered and charred remains that might have made it to some area of Earth that was unlikely to be the territory of a strategic adversary of the United States.

11. Another factor is that ballistic missiles can be equipped with countermeasures $(\mathrm{CM})$ to defeat $\mathrm{BMD}$, which would be impractical for satellites to use, and which, in any case, they are not equipped with (whereas BMs, being on the ground, can always be refitted with new CMs to frustrate any BMD). See Sessler et al. 2000.

12. Burnout speed is the speed a rocket will have accelerated to when it has depleted its fuel. To be unambiguous, its definition must neglect losses due to air resistance and climbing against gravity. But it is often treated more casually, and such losses, for typical flight profiles, may be included in quoted values.

13. For India, see Samson 2011; for France, see Svitak 2011.

14. See, for example, the graph of "Worldwide Nuclear Testing, 1945-1998" posted at Wikipedia 2011.

15. The 1967 Treaty on Principles Governing the Activities of States in the Exploration and Use of Outer Space, Including the Moon and other Celestial Bodies, known as the Outer Space Treaty, mandates that "States Parties to the 
Treaty undertake not to place in orbit around the Earth any objects carrying nuclear weapons or any other kinds of weapons of mass destruction, install such weapons on celestial bodies, or station such weapons in outer space in any other manner." This has never been understood to constitute a ban on nuclear-armed ballistic missiles.

16. It is difficult to imagine any circumstances in which the use of a KEASAT could reduce the creation of outer-space debris, but other forms of "damage or destruction of outer space objects" might.

17. In theory, such use would have to be limited to wars waged in selfdefense "in accordance with the United Nations Charter"; otherwise, under the Charter, the United Nations would be prone to take action against the state waging aggressive war. However, the author is not aware of any recent wars in which all belligerent parties did not maintain that their actions, however aggressive, were justified by the inherent right of individual or collective self-defense in accordance with the UN Charter.

18. This is the author's interpretation of confidential statements made by an administration official, as well as reading of the political situation with respect to code adoption. As of July 2011, no decision has been announced, the Pentagon had not completed its review of the code, and conservative lawmakers and policy analysts had staked out a position in opposition to it (Lake 2011; Kueter 2011).

19. Official Chinese statements about the idea of a Code of Conduct are hard to locate, and China has not responded to the EU draft, while US officials have repeatedly expressed a favorable disposition toward it. Chinese participants in the Honolulu workshop confirmed that the code is generally viewed in China as inadequate and an attempt to deflect China's proposal of a treaty banning the placement of weapons in space. In other forums, Chinese analysts and officials have expressed the view that China would not want to be isolated and would probably join the code if a majority of spacefaring nations did likewise.

20. "Above the atmosphere" can be defined arbitrarily as any altitude greater than $100 \mathrm{~km}$, or somewhat less arbitrarily as $85 \mathrm{~km}$, the upper limit of the mesosphere, in which reentering objects burn.

\section{References}

Brinton, Turner. 2011. "U.S. Military Satellites Achieve 'Holy Grail' of Missile Defense." Space News, March 23, at www.space.com.

Butt, Yousaf. 2008. "Technical Comments on the U.S. Satellite Shootdown." Bulletin of the Atomic Scientists Web Edition, August 21, at www.the bulletin.org.

Cartwright, James. 2008. “Destruction of Spy Satellite.” Department of Defense Briefing, February 21, C-SPAN Video Library, at www.c-spanvideo.org.

Chen, Stephen. 2010. "Mid-Space Missile Test Marks Milestone for Defence Strategy." South China Morning Post, January 13.

Claremont Institutes. Undated. "Ground-Based Interceptor (GBI)." Missile Threat.com, at www.missilethreat.com. 
Clinton, Hillary Rodham. 2007. "Senator Clinton Questions Vice Admiral John M. McConnell." Press Release, February 27, archived at http://web .archive.org.

Council of the European Union. 2008. "Council Conclusions and Draft Code of Conduct for Outer Space Activities.” Document No. 17175/08, at http:// register.consilium.europa.eu.

— 2010. "Council Conclusions Concerning the Revised Draft Code of Conduct for Outer Space Activities." Document No. 14455/10, at http:// register.consilium.europa.eu.

Covault, Craig. 2007. "Chinese Test Anti-Satellite Weapon.” Aviation Week \& Space Technology, January 17.

DPA (German Press Agency). 2007. "Chinese Deny Participation in Outer Space Arms Race." The Raw Story, January 19, at www.rawstory.com.

Elegant, Simon, and Mark Thompson. 2007. "Why China's Missile Test Is Troubling." Time, January 19, at www.time.com.

Forden, Geoffrey. 2007. "After China's Test: Time for a Limited Ban on AntiSatellite Weapons." Arms Control Today, vol. 37 (April), at www.arms control.org.

Fulghum, David A. 2008. "U.S. Considering Shooting Down Satellite." Aviation Week \& Space Technology, February 12.

Globalsecurity.org. Undated. "DF-11 [CSS-7], DF-11A," at www.globalsecurity.org.

Grego, Laura, and David Wright. 2010. Securing the Skies: Ten Steps the United States Should Take to Improve the Security and Sustainability of Space. Boston: Union of Concerned Scientists.

Hitchens, Theresa. 2007. "U.S.-Sino Relations in Space: From 'War of Words' to Cold War in Space?" China Security, no. 5 (Winter), at www.wsichina .org.

Inside Defense. 2010. "Official: U.S. Still Investigating Claim of Chinese Missile Defense Test." January 13.

InsideDefense.com. 2008. "Total Cost for Shoot-Down of Failed NRO Satellite Climbs Higher.” May 12.

Jane's Information Group. 2011. "B-611 (CSS-11) (China).” Jane's Strategic Weapon Systems, June 14, at http://articles.janes.com.

Kueter, Jeff. 2011. "Rules of the Road in Space: Does a Code of Conduct Improve U.S. Security?" at www.marshall.org.

Kulacki, Gregory, and Jeffrey Lewis. 2008. "Understanding China's Antisatellite Test." Nonproliferation Review, vol. 15, no. 2, pp. 335-347.

Lake, Eli. 2011. "Republicans Wary of EU Code for Space Activity." Washington Times, February 3.

Liemer, Ross, and Christopher F. Chyba. 2010. "A Verifiable Limited Test Ban for Anti-satellite Weapons." Washington Quarterly, vol. 33, no. 3, pp. 149-163.

MacDonald, Bruce W. 2009a. "Steps to Strategic Security and Stability in Space: A View from the United States." Disarmament Forum, no. 4, at www. unidir.org.

- 2009b. Testimony before the Strategic Forces Subcommittee, House Armed Services Committee. March 18, Council on Foreign Relations, at www.cfr.org. 
McIntyre, Jamie. 2008. "Attempt to Shoot Down Spy Satellite to Cost Up to $\$ 60$ Million." CNN, February 15, at http://articles.cnn.com.

Missile Defense Advocacy Alliance. 2011. "U.S. Missile Defense Intercept Testing History," June, at http://missiledefenseadvocacy.org.

Missile Defense Agency. 2011. "Fact Sheet: Ground-Based Midcourse Defense," at www.mda.mil.

NASA (National Aeronautics and Space Administration). 2010. "Top Ten Satellite Breakups." Orbital Debris Quarterly News, vol. 20, no. 14, at http://orbitaldebris.jsc.nasa.gov.

Oberg, James E. 2009. "Down in Flames." New Atlantis, no. 24 (Spring), at www.thenewatlantis.com.

O'Reilly, Patrick. 2011. “General Patrick O'Reilly Remarks on U.S. Missile Defense Plans." March 21, at www.c-spanvideo.org.

Samson, Victoria. 2010. American Missile Defense: A Guide to the Issues. New York: Praeger.

—. 2011. "India and Space Security." Space Review, May 9, at www.the spacereview.com.

“Sea-based Missile Defense Flight Test Results in Successful Intercept.” 2011. Missile Defence Agency, News Release, April 15, at www.mda.mil.

Sessler, Andrew M., John M. Cornwall, Bob Dietz, Steve Fetter, Sherman Frankel, Richard L. Garwin, Kurt Gottfried, Lisbeth Gronlund, George N. Lewis, Theodore A. Postol, and David C. Wright. 2000. Countermeasures: A Technical Evaluation of the Operational Effectiveness of the Planned US National Missile Defense System. Boston: Union of Concerned Scientists.

Svitak, Amy. 2011. "Astrium to Pitch Missile Defense to France." Aviation Week.com, June 22, at www.aviationweek.com.

US Department of Defense. 2008. "DoD Succeeds in Intercepting NonFunctioning Satellite." News Release, February 20, at www.defense.gov/.

WikiLeaks. 2011a. "China's Angst over U.S. Satellite Interception." The Telegraph, February 2, at www.telegraph.co.uk.

- 2011b. "Demarche Following China's January 2010 Intercept FlightTest." The Telegraph, February 2, at www.telegraph.co.uk.

—. 2011c. "Request to Allies for New Demarche to China Regarding China's January 2007 Anti-Satellite Test." The Telegraph, February 2, at www.telegraph.co.uk.

_ 2011d. "6.1.2008: Second Demarche for China Regarding China's January 2007 Anti-Satellite Test." Aftenposten.no Wikileaks Dokument, at www.aftenposten.no.

Wikipedia. 2011. "Nuclear Weapons Testing," at http://en.wikipedia.org.

Xinhua. 2008. "China Urges U.S. to Provide Data on Satellite Shootdown." February 21 , at http://news.xinhuanet.com.

2010. "China Conducts Test on Ground-based Midcourse Missile Interception." January 11, at http://news.xinhuanet.com.

Yu, Verna. 2007. "China Confirms Anti-Satellite Weapon Test But Says Nothing to Fear." Agence France-Presse, January 23, at www.spacewar.com. 


\section{LYNNE RIENNER PUBLISHERS}

FORTHCOMING!

Taiwan's

Political Economy:

Meeting Challenges,

Pursuing Progress

Cal Clark \& Alexander C. Tan

CC $\mathrm{n}$ excellent study of Taiwan's

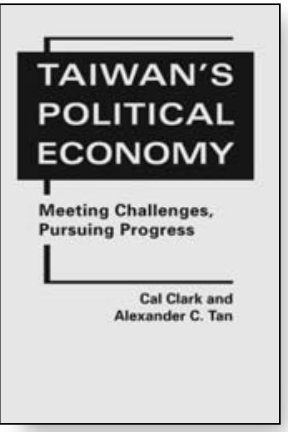

1 political economy ... persuasive and interesting." -Wei-chin Lee, Wake Forest University

Taiwan's economic and political transformation was once considered a model for developing nations, but in recent decades, the momentum has stalled. Why? Cal Clark and Alexander Tan explain the country's paradoxical political economy, tracing its achievements and exploring its challenges.

The authors appraise Taiwan's hard-won accomplishmentsa legitimate democracy and a prosperous society-and also investigate the stubborn institutional legacies undermining its progress. Without discounting Taiwan's significant stress and turmoil, they provide ample evidence to support optimism about its future.

December 2011/ca. 210 pages • hc $\$ 55$

CELEBRATING 28 YEARS OF INDEPENDENT PUBLISHING 1800 30th Street • Boulder, CO 80301 • Tel: 303-444-6684 • FAX: 303-444-0824 www.rienner.com 